\title{
A charge como fonte histórica e ferramenta didática no ensino de História
}

Marcelo Romero*

\begin{abstract}
Resumo:
Essa pesquisa objetiva desenvolver entre os alunos da educação básica os procedimentos característicos da investigação de documentos imagéticos por meio da realização de atividades voltadas para a constituição de uma análise histórica da charge, como a produção de fichas técnicas de análise e de inventários temáticos. Pretende, assim, contribuir para a compreensão de que a investigação histórica se realiza em meio à multiplicidade de procedimentos metodológicos e fontes históricas existentes e/ou disponíveis, além de fomentar o processo de construção do conceito de tempo histórico por meio da prática de identificação das diferentes temporalidades existentes em um dado contexto. Os resultados até aqui obtidos originaram um banco de dados com o material produzido pelos estudantes, cuja análise será objeto de outra publicação, além da produção de material didático sobre os conteúdos selecionados para o desenvolvimento da pesquisa até o momento.
\end{abstract}

\section{Palavras-chave:}

Ensino de História. Charge. Metodologia de ensino.

\begin{abstract}
:
This research aims to develop the standard procedures for image document investigation by middle school students through activities towards historical analysis of cartoons, as production of analytical technical cards and composition summary. It intends to contribute to the understanding that historical investigation is performed by multiple methodological procedures and existent/available historical evidences. Besides that, ignite the construction process about the concept of historical time through practice of identification of different existent temporalities in a certain context. The results obtained so far originated a databank of material produced by the students, which its analysis will be described in future publication, as selected learning material used for the research so far.
\end{abstract}

\section{Keywords:}

History teaching. Cartoon. Teaching methodology.

\footnotetext{
* Professor do Departamento de Ciências Humanas do Colégio de Aplicação da Universidade Federal de Juiz de Fora - UFJF. E-mail: mromerobr@gmail.com. ORCID iD: https://orcid.org/0000-0002-2787-4870.
} 


\section{Introdução}

Essa pesquisa desenvolve uma metodologia de ensino voltada para aproximar os alunos da educação básica dos procedimentos característicos da investigação histórica por meio da análise de documentos imagéticos como a charge. Procura, com isso, estimular a percepção de que a construção do saber histórico se realiza em meio a uma diversidade de fontes históricas e procedimentos metodológicos. A proposta orienta-se também para o processo de construção do conceito de tempo histórico, ensejando a prática de identificação das distintas temporalidades existentes em um determinado contexto histórico.

Iniciada em 2017, a pesquisa é desenvolvida no Colégio de Aplicação da Universidade Federal de Juiz de Fora (UFJF) com estudantes do $9^{\circ}$ ano do Ensino Fundamental. Desdobra-se de tese de doutoramento ${ }^{1}$ e resulta do projeto acadêmico apresentado para o concurso público para seleção de professor de história da instituição em 2016. Planejada ao longo de 2017, foi executada no ano letivo de 2018 com a primeira temática selecionada e, em 2019, já com outra temática, oferecida em formato de oficina para um grupo de alunos dinamarqueses em intercâmbio no Brasil. O material produzido pelos alunos durante essas duas iniciativas será objeto de análise em outra publicação. Neste artigo discutem-se as questões relativas à perspectiva teórico-metodológica da análise da charge no ensino de história e os aspectos atinentes ao planejamento da pesquisa.

A primeira temática trabalhada circunscreveu-se à questão da participação política no Brasil contemporâneo (1985-2015), privilegiando a adaptação de procedimentos característicos da metodologia de análise histórica da charge por meio da elaboração de práticas e atividades pedagógicas, como a produção do inventário temático e de fichas técnicas de análise de imagens. Voltou-se para o desenvolvimento e a constituição da proficiência necessária à problematização da historicidade das práticas políticas dos atores sociais à luz da diversidade de fontes históricas e gêneros textuais existentes e, assim, procurou favorecer a aproximação do aluno junto às práticas e métodos concernentes à investigação histórica.

\section{Análise histórica da charge no ensino de História: um referencial teórico-metodológico}

A hipótese aventada é a de que a charge pode se constituir em valioso instrumento cognitivo, especialmente quando concebida como obra de arte com o potencial para a explicitação da política. Entende-se, ainda, que o trabalho com a temática acerca da participação política por meio de uma prática docente que recorra à metodologia de análise histórica de imagens de um modo geral, e da charge em particular, oferece substratos que podem colaborar para a efetivação da proposta de construção do saber histórico escolar relacionado à formação para o exercício da cidadania.

Parte-se do pressuposto de que as imagens não dispõem de autonomia interpretativa (GINZBURG, 1989) e que a sua adequada compreensão demanda o contraste das informações ali obtidas com os demais registros históricos passíveis de serem relacionados direta ou indiretamente à(s) imagem(ns) pesquisada(s). A admissão de tal premissa conduz a análise ao cotejamento das charges com outros registros históricos disponíveis, tanto para que a sua mensagem possa ser adequadamente inferida, quanto para que a sua análise contribua para fazer emergir, ao mesmo tempo, as particularidades que lhe caracterizam como fonte histórica singular e profícua ferramenta didática.

Dessa forma, o referencial teórico-metodológico da investigação situa-se, por um lado, em um ponto de encontro epistemológico entre a história da arte (GOMBRICH, 2007) e a história política (POCOCK, 2003) e, por outro, na apropriação e ressignificação dessas “operações historiográficas” (CERTEAU, 2017) pela prática docente no ensino de história (MONTEIRO, 2011; BITTENCOURT, 2009). Assim, os proce-

1. ROMERO, Marcelo. O governo Fernando Henrique Cardoso na charge de Angeli: os tons e contornos da crítica política no traço do artista. 2015. Tese (Doutorado em História) - Universidade Federal de Juiz de Fora, Juiz de Fora, 2015. 
dimentos metodológicos foram dispostos da seguinte maneira: 1) levantamento bibliográfico e das fontes imagéticas correlatas ao período recortado; 2) leitura da bibliografia e análise das fontes; 3) sistematização dos dados no inventário temático e nas fichas técnicas de análise; 4) elaboração e aplicação das atividades pedagógicas sugeridas por meio do recurso à metodologia de análise da charge; 5) avaliação dos resultados alcançados frente aos objetivos estipulados; 6) constituição de um banco de dados para elaboração de material didático relativo às temáticas selecionadas.

Os resultados almejados com a elaboração das referidas atividades didático-pedagógicas abrangem um rol significativo de conhecimentos e saberes a serem desenvolvidos como, por exemplo, o de: a) compreender que a investigação histórica se realiza em meio à multiplicidade de procedimentos metodológicos e fontes históricas existentes e/ou disponíveis; b) reconhecer a historicidade que permeia qualquer atividade política; c) identificar a diversidade de linguagens, verbais e imagéticas, utilizadas pelos atores históricos; d) apreender a dinâmica comunicativa da linguagem da charge por meio da identificação dos elementos que a constituem; e, enfim, e) perceber o potencial da obra de arte para proporcionar experiências e estímulos que contribuem para o desenvolvimento cognitivo dos indivíduos, particularmente no que tange ao processo de atribuição de sentidos e significados que atores históricos imputam às relações sociais.

A contribuição desse processo de problematização da política por meio do reconhecimento das suas relações com contextos históricos distintos se evidencia no recurso à metodologia de análise da charge ao atrelar-se à discussão em torno da epistemologia das fontes históricas. Compreende-se, dessa maneira, que a charge pode ser considerada um "documento/monumento", ou seja, um registro histórico daquilo que sobreviveu como "herança do passado" e, desse modo, suscetível a se tornar objeto da prática do historiador (LE GOFF, 1996, p. 547-548).

Essa perspectiva pode ser aproximada à de Carlo Ginzburg e seu paradigma indiciário, especialmente em relação à sua inferência sobre ser o passado factível de investigação, compreensão e explicação, não obstante a sua opacidade (LIMA JR., 2009). A respeito da impossibilidade de se traduzir o passado "exatamente" como ele teria ocorrido, o historiador italiano propõe que se enfrente tal opacidade atendo-se aos indícios legados, aos "sinais" indelevelmente marcados nos registros históricos, e que fornecem ao historiador atento aos seus detalhes, tal qual o detetive às suas pistas, os instrumentos que possibilitam a reconstrução do contexto histórico a ser inquirido (GINZBURG, 1989).

Assim, com o objetivo de se chegar a uma epistemologia da charge que a perceba como fonte histórica singular e laboriosa ferramenta didática é possível estabelecer uma analogia entre a sua contribuição para desvelar a opacidade do passado, assim como para desnudar a opacidade que caracteriza a política, pois, de acordo com Cesar Kiraly (2016, grifos do autor), “[...] a política se esconde [...]", demandando que seja revelada. Explicitá-la é, contudo, oportunidade para uma "sorte de ardil", pois, menos do que saber "[...] o que é política - já que a política nem sempre é ou não é - importa reconhecer quando é política". A obra de arte que mobiliza signos políticos e não se deixa capturar pelo objeto de sua crítica, a política, enseja, portanto, a ocasião para que se reconheça os estratagemas subjacentes às práticas políticas. Este é o "belo ardil da experiência da arte sobre a política", a oportunidade em que se granjeia à obra de arte a capacidade de desvelar a opacidade da política (KIRALY, 2016).

Elevada à qualidade de fonte histórica a charge exibe sua singularidade, portanto, ao se expressar como obra de arte e crônica jornalística (GOMBRICH, 2012; MOTTA, 2013, 2006) e ao possibilitar "[...] que o historiador acesse a sensibilidade de uma época [...]" (ARAÚJO; SILVA; SANTOS, 2013, p. 9, grifo das autoras), demonstrando, assim, o seu potencial para a identificação da historicidade inerente às práticas políticas, especialmente ao traduzir a multiplicidade de interesses de que tais práticas se revestem.

Depreende-se, portanto, que a opção por privilegiar a charge como fonte histórica singular e dela se valer como ferramenta didática para o desenvolvimento da temática acerca da participação política no Brasil contemporâneo oferece, a um só tempo, duplo benefício: contribui para dissipar a opacidade do passado, assim como para evidenciar a opacidade da política.

O desenvolvimento da temática acerca da participação política no Brasil contemporâneo por meio do recurso à metodologia de análise da charge pode ser abordado ao se analisar o motivo artístico (PANOFSKY, 
2009) referente à manifestação de rua na sua relação com as estratégias de enunciação características da tradição imagética desse gênero artístico (GOMBRICH, 2012, 2007, 1999, 1938) ${ }^{2}$. Em uma abordagem nesse sentido, o motivo artístico da manifestação de rua contribui para promover o trânsito ao longo de todo o período recortado e o recuo no tempo para a sua devida contextualização, articulando, assim, as dimensões sincrônica e diacrônica que constituem a análise das temporalidades subjacentes à dinâmica comunicativa da linguagem da charge, o que favorece o processo de construção da pluralidade característica do conceito de tempo histórico, destes "tempos múltiplos e contraditórios da vida dos homens, que não são apenas a substância do passado, mas também a base da atual vida social” (BRAUDEL, 1965, p. 262).

Como assinalado pela historiadora Circe Bittencourt, a proposta de formação para a cidadania, sugerida como um dos eixos temáticos dos Parâmetros Curriculares Nacionais de História, não se institui sem o desenvolvimento de uma determinada formação política propriamente dita (BITTENCOURT, 2009). Assim, depreende-se que a construção do saber histórico escolar relacionada à formação para o exercício da cidadania se viabiliza na medida em que erige a proficiência necessária à problematização da historicidade imanente às práticas políticas.

Por sua vez, a prática docente abriga diversificados procedimentos para a construção dos acessos a contextos históricos passados e o recurso ao tempo presente é, reconhecidamente, um bom ponto de partida. Deve-se, contudo, atentar para as especificidades características desse campo da investigação histórica, até para que seu manejo permita explorar todas as vantagens que a sua utilização oferece. Dessa forma, de acordo com as historiadoras Marieta de M. Ferreira e Lucília N. de A. Delgado, a singularidade intrínseca ao "regime de historicidade do tempo presente" o torna

[...] bastante peculiar e inclui diferentes dimensões, tais como: processo histórico marcado por experiências ainda vivas, com tensões e repercussões de curto prazo; um sentido de tempo provisório, com simbiose entre memória e história; sujeitos históricos ainda vivos e ativos; produção de fontes históricas inseridas nos processos de transformação em curso; temporalidade em curso próximo ou contíguo ao da pesquisa. (FERREIRA; DELGADO, 2013, p. 25).

Nesse sentido, o recurso ao tempo presente, usual na prática docente de construção dos acessos ao passado, tem na charge uma vantajosa ferramenta didática, pois a "efemeridade" das temáticas a que se refere (MIANI, 2012, p. 39) decorre de características que lhe são intrínsecas. Isso porque a charge é expressão do comentário diário que os desenhistas elaboram sobre os acontecimentos recentes e, tal qual a notícia do dia, "[...] mantém sua força e ação num espaço breve de tempo em que os acontecimentos a que se refere permanecem na memória individual e social imediata” (GRUDZINSKI, 2009, p. 7).

Outro aspecto relevante diz respeito à capacidade da charge de sintetizar os eventos políticos do contexto histórico em que ela foi produzida, resultante do objetivo do artista interessado em transmitir a sua mensagem o mais concisamente possível, pois "[...] o desenhista moderno trabalha geralmente para um público ocupado que quer captar tudo num simples olhar [...]" (GOMBRICH, 1999, p. 134), o que contribui para a apreensão dos traços essenciais do debate político de uma época.

O recurso à charge demonstra-se, com isso, promissora estratégia didática na prática docente de problematizar o passado a partir de questões levantadas sobre o presente. A combinação de ambos no processo de construção do saber histórico escolar - a adoção do tempo presente como ponto de partida e a opção pela análise imagética como estratégia didática - provoca uma ampla gama de relações capazes de, por um lado, estimular a constituição e o desenvolvimento de identidades e memórias, da pluralidade de temporalidades que caracterizam o conceito de tempo histórico, e, por outro, contribuir para a efetivação da proposta de formação para o exercício da cidadania.

2. O que não excluiu a análise de charges em que esse motivo não seja referido, estabelecendo-se tal critério como um pressuposto resultante do levantamento preliminar das fontes imagéticas, a ser verificado ao longo da investigação. Do mesmo modo, tanto quanto possível, outros tipos de imagens devem ser selecionados para a sua comparação com as charges. 
A utilização da metodologia de análise de documentos imagéticos no ensino de história permite a aproximação do aluno da educação básica às práticas que singularizam a investigação histórica.

Pode-se elaborar a aplicação das atividades divididas em, ao menos, dois procedimentos metódicos específicos, porém, complementares, à produção: a) do inventário temático responsável por identificar e relacionar as charges analisadas, estruturado em torno de critérios temático e cronológico; e b) das fichas técnicas individuais de análise das imagens inventariadas, nas quais são contrastadas as informações obtidas com a verificação das diversificadas fontes levantadas para a investigação. Entre outros aspectos, tais procedimentos adquirem, fundamentalmente, o propósito de reconhecer as informações correspondentes às distintas fontes históricas selecionadas para a investigação, e, assim, destacar a especificidade da linguagem própria do documento imagético.

\section{A produção do inventário temático}

Além de identificar e relacionar as fontes imagéticas e se constituir em depositório da dinâmica de levantamento e sistematização dos dados, o inventário temático é uma ferramenta metodológica capaz de estruturar os procedimentos da análise imagética ao longo da investigação, e, igualmente, sistematizar a problemática a ser abordada pela narrativa histórica elaborada para a exposição dos resultados da pesquisa.

A sua realização, portanto, orienta o aluno sobre como proceder ao longo de toda análise imagética, desde o 1) levantamento das fontes e o processo de seleção e identificação das imagens; passando pela 2) verificação das temáticas aludidas na charge e os contextos históricos a que se referem; até o 3) processo de estruturação da narrativa histórica responsável pela exposição dos resultados das pesquisas desenvolvidas pelos estudantes.

Dessa forma, sugere-se ao aluno que considere o inventário temático como uma espécie de mapa, criado para o registro das coordenadas da sua investigação histórica, o que lhe permitirá revisitá-las sempre que necessário ou desejável.

\section{A produção da ficha técnica de análise da charge}

A elaboração das fichas técnicas individuais de análise imagética pelo aluno pressupõe, do mesmo modo, três momentos com finalidades cognitivas e procedimentos metódicos específicos: 1) a análise imagética preliminar; 2) o cotejamento da imagem com os registros históricos correspondentes; e 3) o processo da sistematização dos dados para a explanação dos resultados.

Foram assim divididos, entre outros motivos, por entender-se que no momento da análise imagética preliminar cumpre registrar as apreensões iniciais, justamente porque sabidamente lacunares e, desse modo, evitar confundi-las com as informações obtidas em diferentes fontes históricas, sob o risco do sujeito dessa análise "ler" nas fontes imagéticas "[...] o que já sabe, ou crê saber, por outras vias, e pretende 'demonstrar"” (GINZBURG, 1989, p. 63, grifo do autor).

O momento subsequente, do contraste entre as análises das fontes imagéticas e os demais registros históricos relacionados - agora também alçados à qualidade de fontes históricas -, apura a análise preliminar e produz outra análise imagética, agora mais qualificada, já que melhor informada e, portanto, depurada, em alguma medida, de eventuais incompreensões ou equívocos.

Por sua vez, a transformação dos resultados da análise em uma narrativa histórica decorre da sistematização dos dados da produção das fichas técnicas no inventário temático. Ao destacar na ficha técnica a especificidade da linguagem da charge frente às demais fontes históricas analisadas, o aluno capacita a sua narrativa para o contraste entre a singularidade da linguagem imagética e outros gêneros textuais e estratégias de enunciação utilizadas por diferentes atores sociais em contextos históricos distintos. 
O suporte conferido pela elaboração do inventário temático e a produção das fichas técnicas de análise para a estruturação da narrativa histórica responsável pela exposição dos resultados é vantajoso, portanto, na medida em que enseja no estudante a percepção acerca da multiplicidade de linguagens existentes em um determinado "contexto linguístico", assim como a identificação da diversidade de usos que os atores sociais fizeram de tais linguagens no contexto histórico pesquisado (POCOCK, 2003). Torna-se particularmente favorável, ainda, para o desenvolvimento da compreensão do aluno de que a sua própria narrativa também dispõe dessa variedade de linguagens e gêneros textuais para a sua enunciação.

Entende-se que, assim, a proposta também habilita a investigação para a verificação dos limites e potencialidades da charge em acessar determinado contexto histórico, além de subsidiar a compreensão acerca do potencial da sua utilização como fonte histórica singular e ferramenta didática privilegiada na prática docente de história interessada tanto na constituição da proficiência necessária ao reconhecimento da historicidade inerente às práticas políticas, quanto em auxiliar na efetivação da prática docente de formação para o exercício da cidadania.

\section{Planejamento e execução das atividades}

A aplicação das atividades realizadas em sala de aula inicia-se com o planejamento para a elaboração do inventário temático e a produção da ficha técnica. A execução da proposta pode ser pensada para que cada aluno a realize individualmente ou em grupo. No último caso, os alunos deverão desenvolver as atividades com temas previamente determinados, que podem ser elaborados antecipadamente pelo professor ou em conjunto com os alunos durante a problematização inicial da temática proposta.

A proposição dos temas deve atrelar-se a questões circunscritas às práticas políticas, independentemente do período histórico recortado para o desenvolvimento das atividades. Nesse sentido, tomando como base os elementos constitutivos da dinâmica comunicativa da charge, ao menos sete temas podem ser sugeridos: 1) Caricaturas e governantes; 2) Usos e abusos das figuras de linguagem nas práticas políticas; 3) Os estereótipos do poder; 4) Política(o): um objeto inanimado?; 5) As manifestações políticas da intertextualidade verbal e imagética; 6) O zoológico da política; 7) Os contrastes da participação política.

Esclarecidas as instruções acerca do planejamento das atividades, solicita-se aos alunos que façam um levantamento preliminar das fontes que abordem o período histórico recortado. Em relação ao levantamento das fontes imagéticas, além da charge selecionada para análise, deve-se selecionar também um conjunto de charges (de três a cinco) que contribuam para a análise da primeira. As demais fontes (três a cinco) podem ser escolhidas entre documentos históricos de diferentes gêneros textuais.

A partir daí, apresentam-se aos alunos os modelos do inventário temático e da ficha técnica e prossegue-se com uma explanação visando a caracterizar os elementos constitutivos da linguagem da charge - relacionados na ficha técnica -, assim como as estratégias de enunciação mobilizadas com maior recorrência pelos desenhistas, além de instruí-los sobre os procedimentos necessários para o preenchimento de ambos. Nesse momento importa destacar os elementos que constituem a dinâmica comunicativa da linguagem da charge e as tradições imagéticas conformadoras da sua singularidade, exemplificados por meio da exibição de charges previamente selecionadas para essa finalidade e solicitando aos alunos que identifiquem, nas imagens exibidas, os aspectos assinalados.

De posse das imagens selecionadas no levantamento das fontes realizado anteriormente e da charge escolhida para análise, os alunos concluem a primeira parte da elaboração do inventário temático com o processo de identificação das imagens. A partir desse ponto, a elaboração do inventário temático e a produção da ficha técnica se realizarão concomitantemente, alternando a produção da ficha técnica da charge selecionada para análise e o registro desses dados no inventário temático. Ao término do levantamento, seleção e identificação das imagens no inventário temático, segue-se, portanto, à problematização do tema relativo ao evento social contemporâneo escolhido como ponto de partida para o desenvolvimento dessas atividades. 
Selecione-se, a título de demonstração da aplicação da proposta de pesquisa referente à temática acerca da participação política no Brasil contemporâneo (1985-2015), o motivo artístico da manifestação de rua na sua relação com a dinâmica comunicativa da linguagem da charge. Como evento social contemporâneo para a problematização inicial da temática aludida tome-se como ponto de partida, a título de exemplificação, as manifestações realizadas pelo Movimento Passe Livre (MPL) contra o aumento das tarifas do transporte público na cidade de São Paulo, ocorridas em janeiro de 2016. A seu turno, a imagem selecionada para exemplificação da análise imagética foi a charge do desenhista João Montanaro, publicada no jornal Folha de S. Paulo, aos 22 de junho de 2013.

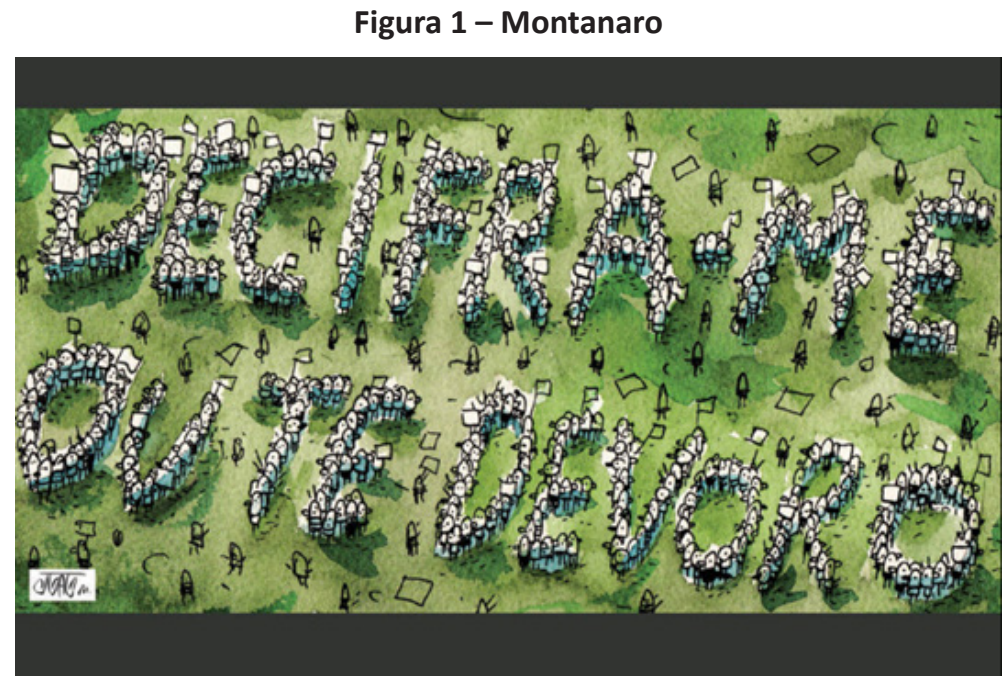

Fonte: MONTANARO, 2013

Esse recorte temporal favorece a problematização da temática, pois, além de adotar o tempo presente como ponto de partida, abarca o período compreendido entre os anos de 2013 e 2015, que adquiriu notoriedade devido à ocorrência de variadas manifestações de rua ${ }^{3}$, trazendo à tona o debate sobre as formas de participação política existentes no país. Procede-se, então, ao registro no inventário temático dos dados produzidos pelos alunos até este momento.

O próximo passo consiste em iniciar a produção da ficha técnica com o desenvolvimento da análise preliminar da charge selecionada. Esse é o momento da análise imagética estritamente falando, ou seja, quando se identificam as primeiras informações sobre a charge e se constituem os dados a serem contrastados com as fontes históricas relacionadas. A seguir, passa-se à contextualização sincrônica da imagem e, de posse do modelo de ficha técnica, alunos e professor desenvolvem a análise preliminar da charge por meio da sua problematização em face aos acontecimentos recentes e do período em que a charge foi produzida.

Assim, na charge selecionada para análise (Figura 1), o desenhista João Montanaro, ao dispor os corpos dos manifestantes e seus cartazes de maneira a formar as palavras que remetem ao enigma da esfinge, utiliza o motivo artístico da manifestação de rua como principal estratégia de enunciação da dinâmica comunicativa da sua charge, ressaltando a intertextualidade existente entre a linguagem verbal e imagética nessa estratégia. Em virtude dessa ênfase, $\mathrm{o}$ artista abdica de outros representativos elementos constitutivos da linguagem desse tipo de imagem para a elaboração da sua estratégia de enunciação, principalmente da técnica de redução caricatural (GOMBRICH, 1999; 2007). Penumbras que reverberam seu enunciado de maneira ainda mais eloquente.

"Decifra-me ou te devoro" foi o enigmático coro imputado pelo artista à multidão que, abrupta e progressivamente, colocou-se a protestar nas ruas de inúmeras cidades do país em junho de 2013,

3. Entre junho de 2013 e janeiro de 2016, além das promovidas pelo MPL, ocorreram manifestações de repercussão nacional: contra a realização da copa do mundo no país (2014); a favor do impeachment da presidente Dilma e da "intervenção militar" (2015); em defesa do governo vigente (2015); e em favor da educação pública (2015) no Paraná, em São Paulo e Goiás, entre outras. 
ampliando o leque de reivindicações das manifestações iniciadas com os protestos do Movimento Passe Livre (MPL) em favor de demandas mais genéricas, como a melhoria dos serviços públicos na área da saúde e da educação. Criado em 2005, o MPL promove manifestações desde então, porém, nenhuma delas desaguou nas repentinas mobilizações que adquiriram dimensões nacionais, como em 2013 (SOUTO, 2013). Nem mesmo posteriormente, em janeiro de 2016, quando o Movimento Passe Livre voltou à carga contra o novo aumento das tarifas. A súbita eclosão e a significativa adesão às manifestações naquele momento específico são, portanto, aspectos que podem se instituir como indícios dos fatores que motivaram (POCOCK, 2003) o artista a enfatizar o que entendeu ser o tom enigmático das manifestações de junho de 2013.

Desse ponto em diante a problematização passa a abarcar também as questões suscitadas pela imagem como, por exemplo, o contraste entre a cor verde do gramado e a branca dos cartazes e manifestantes - a sugerir a esperança que o artista depositou nessas manifestações -, ou a possibilidade de a referência ao enigma da esfinge funcionar como um trocadilho para aludir à violência que caracterizou os protestos. Assim, concluída a análise preliminar, registram-se os dados na ficha técnica e solicita-se aos alunos que tragam para a próxima aula a análise preliminar da imagem que selecionaram.

A contextualização diacrônica da imagem deve intermediar, durante a produção da ficha técnica, a passagem do momento da análise preliminar da charge para o seu cotejamento com as fontes correlatas. Isso porque objetiva-se, também, prover a análise da imagem selecionada de subsídios retirados junto a charges produzidas em outros contextos históricos e, desse modo, favorecer o reconhecimento da "iconosfera" (MENEZES, 2005) que permeia as diferentes formas de participação política existentes no país. Neste momento, utiliza-se o conjunto de imagens selecionadas quando da realização do levantamento preliminar, já relacionadas no inventário temático.

Objetivando a identificação das referências históricas existentes nas práticas políticas do tempo presente, e perseguindo o exemplo do motivo artístico da manifestação de rua, além da sua relação com a dinâmica comunicativa da charge no tempo, dilata-se a problematização da sua dimensão temporal sincrônica para a diacrônica, a fim de propiciar a contextualização histórica da imagem analisada no período recortado. Ao se comparar a charge de João Montanaro de 2013 com a do desenhista Claudius, publicada seis meses após o golpe civil-militar de 1964, é possível ressaltar, portanto, a especificidade do contexto histórico das manifestações de junho de 2013, em que a pauta das reivindicações foi ampliada para além da questão relativa ao aumento da tarifa do transporte público.

Figura 2 - Claudius

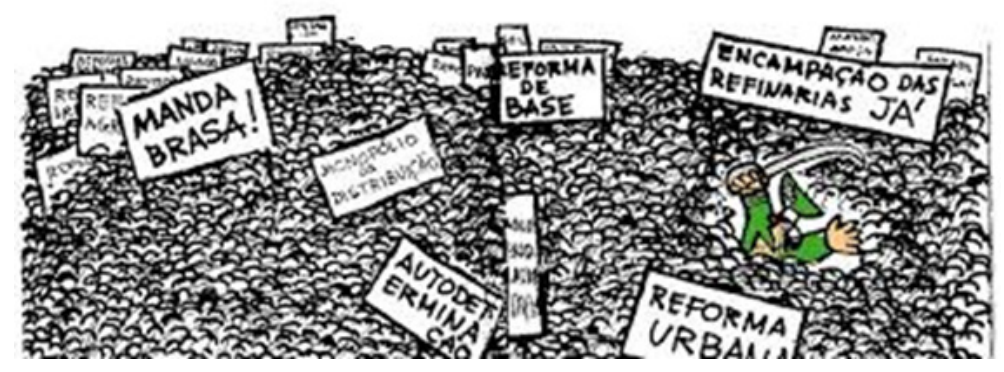

Fonte: CLAUDIUS; JAGUAR; FORTUNA, 1964.

Na charge de Claudius, o militar que se opõe energicamente com sua espada - e aos brados de "teje todo mundo preso!” - à multidão que ostenta suas faixas e cartazes evidencia que o uso dos contrastes, por meio da prática da intertextualidade verbal e imagética, foi a principal estratégia de enunciação elaborada pelo desenhista para expressar a sua crítica ao significado do golpe de 1964 para as mobilizações sociais em curso no país à época (REIS; RIDENTI; MOTTA, 2004).

Por outro lado, contudo, na Figura 2, diferentemente da Figura 1, as reivindicações foram explicitadas nas faixas e nos cartazes empunhados pela multidão e demonstram-se tão amplas como variadas. Ao menos é o que se pode depreender das alusões às chamadas "reformas de base" - como a reforma urbana -, às questões 
relativas ao monopólio estatal da extração e distribuição do petróleo no Brasil e, até mesmo, a reivindicações ainda mais genéricas, como a do cartaz que exclama por "autodeterminação".

Ressalte-se, ainda, que na charge de Claudius o contraste entre os estereótipos do militar - metonímia para aludir às Forças Armadas - e dos manifestantes, demonstra a intenção do artista em opor, respectivamente, o Estado autoritário surgido com o golpe de 1964 e a sua repressão às reivindicações, presentes em significativas parcelas da sociedade brasileira, em favor da ampliação do processo de democratização social no país.

A estratégia de enunciação da charge de Claudius é muito semelhante à da famosa charge de Henfil sobre as manifestações das "Diretas Já!", publicada em 1984, no contexto de "liberalização do regime" (SALLUM JR., 1996). Em 1984, assim como Claudius em 1964, Henfil utilizou-se do motivo artístico da manifestação de rua e do contraste entre a multidão e o indivíduo com o intuito de provocar a oposição, respectivamente, entre a sociedade brasileira e o Estado proveniente do golpe de 1964. Ainda da mesma maneira que na charge de Claudius, o contraste provocado por Henfil destacou o protagonismo da sociedade brasileira na sua relação com o Estado e, igualmente, explicitou nos cartazes e nas faixas dos manifestantes as suas reivindicações - o que não se observa na charge de João Montanaro, publicada em 2013.

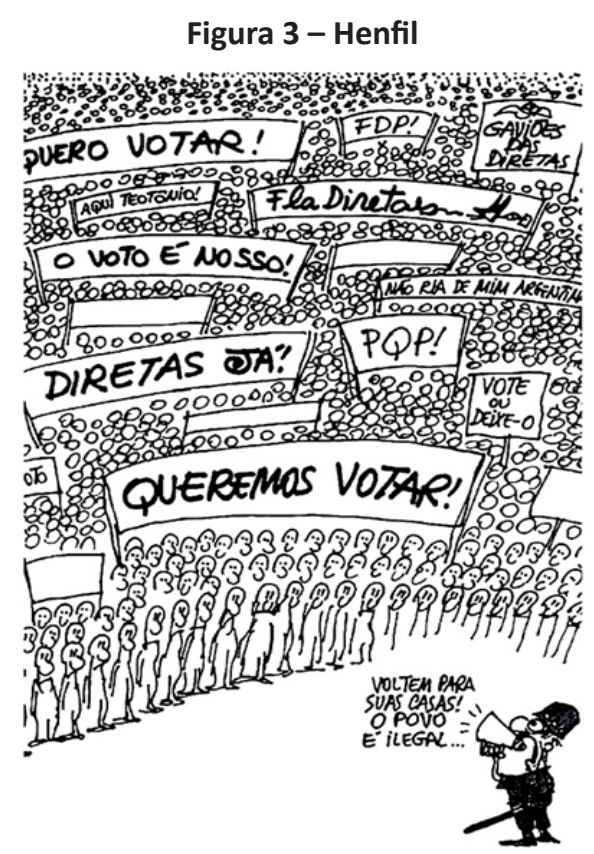

Fonte: Blog Zona Curva4.

Na charge de Henfil, no entanto, o estereótipo do manifestante opõe ao militar os anseios pelo restabelecimento das eleições diretas para a presidência da República no país, e, não mais as reivindicações pelas "reformas de base", cerceadas pelo golpe de Estado, como no desenho de Claudius.

O motivo das manifestações de rua também está presente na charge de Glauco, publicada em 1978, ainda sob a vigência da ditadura inaugurada em 1964, entretanto, em um contexto histórico também diverso, no qual se deram a extinção do Ato Institucional n. 5 e em que adquiriram vulto as reivindicações em favor da anistia aos opositores políticos da ditadura. Ainda assim, da mesma maneira que Claudius, em 1964, e Henfil, em 1984, Glauco se vale do contraste entre os estereótipos dos militares e manifestantes para aludir à oposição entre o Estado e a sociedade no Brasil. A utilização que realiza da prática da intertextualidade verbal e imagética é, todavia, diversa da que Claudius e Henfil fizeram dela.

4. Disponível em: http://zonacurva.com.br/wp-content/uploads/2014/02/5-de-fevereiro-henfil_o-povo-e-ilegal-ditadura-militar-foto-1-1.jpg. Acesso em: 30 jan. 2016. 
Figura 4 - Glauco

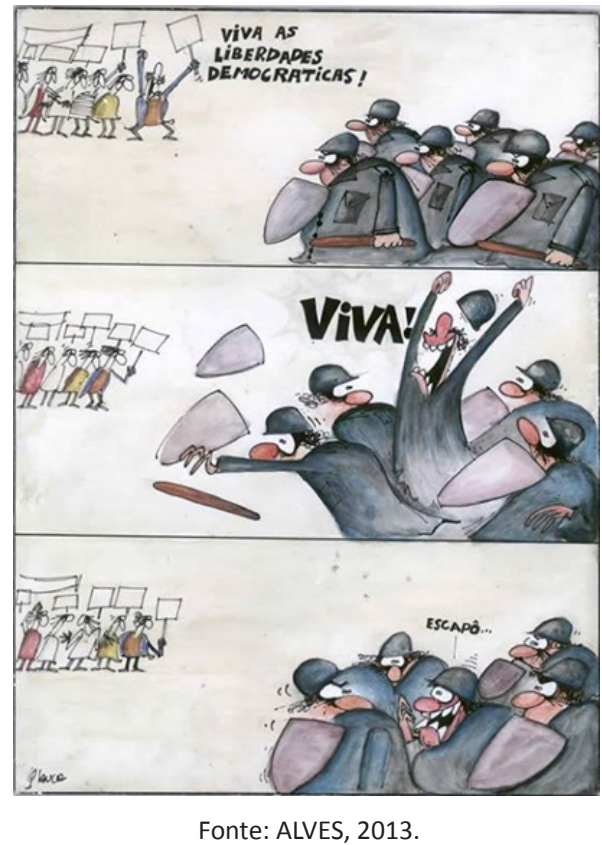

O uso que Glauco fez do recurso à intertextualidade imagética e verbal demonstra que o desenhista se referia a uma pauta mais ampla de reivindicações - as "liberdades democráticas" - do que a expressa na charge de Henfil sobre o movimento das “Diretas Já!", porém, mais restrita que a de Claudius, em que sobressaía a demanda pelas "reformas de base". Com o recurso à linguagem característica das histórias em quadrinhos e/ou das tirinhas de jornais, a charge de Glauco levanta também a ideia de que a adesão à causa democrática estava generalizada de tal forma que podia ser aventada, inclusive, entre as forças policiais mobilizadas para a sua repressão. Assim, Glauco evidencia o paroxismo a que chegou o autoritarismo praticado pelo Estado brasileiro à época.

Esse foi, inclusive, o mote levantado pela desenhista Laerte em junho de 2013, quando resgatou a dinâmica comunicativa da charge de Glauco para denunciar a violência com que a polícia militar reprimiu as “jornadas de junho" e, igualmente, sugerir a sua adesão aos protestos. Dessa forma, o desenho de Glauco de 1978 se apresenta como um valioso exemplar da charge que se transforma em cartum, pois expressa valores que passaram a ser considerados como "universais", tais quais as aludidas "liberdades democráticas" (ALVES, 2013).

Figura 5 - Laerte

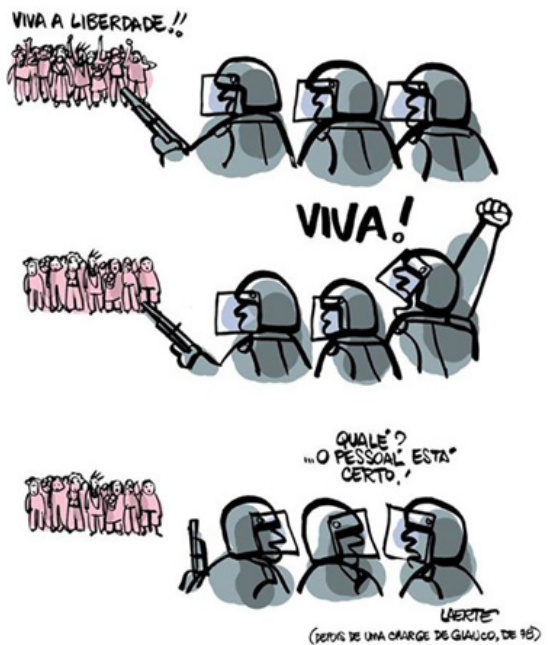

Fonte: ALVES, 2013 
De volta à figura 1, a análise da charge de João Montanaro - e sua ênfase no enigma da esfinge -, agora se encontra munida de maiores subsídios para o contraste com as fontes correspondentes. Antes, contudo, frente às informações angariadas na sua comparação com as Figuras 2, 3, 4 e 5, importa recolocar algumas questões registradas durante a análise imagética preliminar.

Uma menção acerca da pauta das reivindicações de junho de 2013, por exemplo, adquiriu pertinência. Nas imagens em que se compararam as representações dos desenhistas Claudius, em 1964 (Figura 2), Glauco, em 1978 (Figura 4) e Henfil, em 1984 (Figura 3), as reivindicações das manifestações de rua durante os respectivos contextos históricos - ora mais abrangentes, ora mais circunscritas - sempre estiveram explicitadas nas imagens, mesmo na charge da desenhista Laerte (Figura 5) - publicada em junho de 2013, por mais genérica que seja a reivindicação por "liberdade".

$\mathrm{Na}$ charge de João Montanaro (Figura 1), contudo, isso não se observa. Ao contrário. E este silêncio adquire relevo no contraste promovido pelo artista entre o verde do gramado e o espaço deixado em branco nas faixas, bandeiras e nos cartazes da multidão de manifestantes, disposta pelo artista - conforme mencionado - de maneira a ressaltar o tom enigmático das suas reivindicações. Depois de vinte e cinco anos de promulgada a Constituição de 1988, o contexto histórico e a pauta das manifestações de junho de 2013 são, portanto, bastante diversos dos aludidos pelas charges em relação às reivindicações pelas "reformas de base", em 1964, pelas “liberdades democráticas”, em 1978, e pelas “Diretas Já!", em 1984.

Diferentemente das últimas imagens, em que os artistas se utilizaram dos estereótipos do militar e do manifestante para sugerir a oposição entre o Estado e a sociedade - entre autoritarismo e democratização -, o contraste presente na charge de João Montanaro se realiza entre o estereótipo do manifestante de junho de 2013 e o leitor do jornal Folha de São Paulo. Desse modo, o artista desloca o leitor da sua condição de espectador e o insere no turbilhão do conflito observado nas ruas do país, especialmente ao remeter-se ao enigma da esfinge e, com isso, ao desafortunado destino que ela reserva àqueles que falharam em desvendá-lo.

Desse modo, a "sensibilidade de uma época" (ARAÚJO; SILVA; SANTOS, 2013, p. 9, grifo das autoras) que a charge de João Montanaro permite capturar torna-se perceptível, entre outros aspectos, na dificuldade que os contemporâneos dos fatos - e talvez, até mesmo, parte significativa dos seus protagonistas -, demonstraram para compreender os significados que as manifestações de junho de 2013 adquiriram no momento em que ocorreram. Liste-se, entre eles, o próprio artista.

Tais indícios ganham vulto no segundo momento da produção da ficha técnica, o do cotejamento entre a análise imagética preliminar e os registros históricos correspondentes. Ao se contrastar a análise da charge de João Montanaro às do editorial e das crônicas dispostas na mesma página do jornal no dia em que a imagem foi publicada, apreende-se que, cada qual a seu modo, e com interesses e opiniões - na maioria das vezes - distintos entre si, também expressaram as suas dificuldades em compreender as motivações que levaram a manifestações tão amplas e contundentes 5 . Percepção igualmente observada em parte da literatura especializada que se dedicou ao assunto quando as manifestações eclodiram (SOUTO, 2013; CARVALHO, 2013).

Assim, após o recolhimento da ficha técnica da análise preliminar realizada por cada aluno ou pelos grupos, retoma-se a problematização sobre a questão das manifestações de rua como forma de participação política no Brasil, enfatizando-se a complexidade de sentidos e significados que foram atribuídos às manifestações de junho de 2013, como a charge de João Montanaro sugere e as fontes até aqui contrastadas demonstraram.

Este também é o momento em que os alunos promovem a verificação da temática e do contexto histórico da charge no inventário temático, sistematizados anteriormente na análise imagética preliminar, retificando, em virtude do contraste entre as fontes, eventuais equívocos ou lacunas existentes.

Nas aulas subsequentes encaminham-se os procedimentos necessários à sistematização dos dados no Inventário Temático, agora munido das informações decorrentes da segunda análise imagética - e à elaboração da narrativa histórica criada pelos alunos para a exposição dos resultados da sua pesquisa.

5. Cf. Jornal Folha de S. Paulo, 22 jun. 2013. 
Nesse ponto, a sugestão é para que os alunos construam a sua narrativa histórica por meio de um texto dissertativo, já que tal prática consiste em um processo cognitivo em si mesmo. Por outro lado, solicita-se aos alunos que elaborem, também, uma exposição da sua narrativa que se aproprie de outras linguagens ou gêneros textuais. Esta pode se valer do vasto cabedal de iniciativas existentes nesse sentido, como a tradicional oficina de cartazes - bastante apropriada para o exemplo em tela -, ou as linguagens desenvolvidas mais recentemente, como as utilizadas em redes sociais como o Facebook, na rede mundial de computadores, a internet.

Ante ao exposto, o exemplo do motivo artístico das manifestações de rua na charge permite sugerir que, na sua relação com o Estado, o protagonismo político da sociedade no Brasil tem raízes históricas, sobretudo em mobilizações populares em favor da ampliação do processo de democratização social no país. Do mesmo modo, por outro lado, é possível observar o lastro histórico que também garante a sobrevivência de práticas políticas autoritárias, capazes de mobilizar adeptos e simpatizantes, e que remontam o regime republicano brasileiro ao seu passado ditatorial, especialmente visível - e em diferentes contextos históricos - na repressão policial a tais manifestações, para o que a análise da charge também colabora.

\section{Considerações finais}

Para a realização da pesquisa no ano letivo de 2018, investigaram-se as manifestações ocorridas no Brasil entre junho e julho de 2013, já que o motivo artístico das manifestações de rua tornou-se propício para o desenvolvimento dessa temática. Em duplas, os estudantes escolheram uma entre as 15 charges previamente selecionadas para ensejarem a sua pesquisa. A execução do planejamento evidenciou alguns limites e potencialidades da proposta sugerida. As restrições demonstraram-se especialmente visíveis quanto ao procedimento de leitura e análise do jornal em que a charge selecionada por eles para a análise foi publicada, embora algumas duplas tenham realizado essa etapa do processo de investigação com interesse e diligência. As fontes que encontraram maior receptividade entre os estudantes foram as demais charges às quais se recorreu para oferecer suporte à charge selecionada, além de um documentário sobre o tema. Em razão de dificuldades relacionadas ao cronograma de execução das atividades, que o tornaram mais exíguo, não foi possível que a produção textual fosse elaborada em formato de artigo científico. Isso não impediu, contudo, que os estudantes apresentassem os seus trabalhos para alunos de outras séries sob a forma de painéis, como é próprio da apresentação de trabalhos em eventos científicos.

No que concerne ao desenvolvimento do conceito de tempo histórico e à compreensão acerca da multiplicidade de fontes e métodos abarcados pela investigação histórica, foi possível observar que os estudantes do $9^{\circ}$ ano do Ensino Fundamental não demonstraram dificuldades em se familiarizar com os procedimentos característicos da análise de documentos imagéticos, como a elaboração das fichas técnicas de análise e do inventário temático, evidenciando um desenvolvimento qualitativo no que diz respeito à capacidade de identificar as diferentes temporalidades existentes em um determinado contexto histórico, demonstrando-se, até mesmo, mais afeitos à análise das fontes imagéticas em relação às textuais.

Depreende-se, portanto, que a iniciativa de se recorrer à análise histórica da charge permite engendrar a produção de material didático sobre os conteúdos selecionados para o desenvolvimento da pesquisa; privilegiar a utilização de fontes históricas na construção do saber histórico escolar; desenvolver os conhecimentos e saberes demandados para a disciplina de história no $9^{\circ}$ ano do Ensino Fundamental; além de contribuir para o processo de alfabetização/letramento científico ${ }^{6}$ na educação básica no âmbito de ensino de história.

6. Para a discussão acerca da alfabetização/letramento científico no ensino de ciências cf. CUNHA, Rodrigo Bastos. O que significa alfabetização ou letramento para os pesquisadores da educação científica e qual o impacto desses conceitos no ensino de ciências. Ciênc. Educ., Bauru, v. 24, n. 1, p. 27-41, 2018. 


\section{Referências}

ALVES, Rodrigo. Viva as liberdades democráticas! Jornal de Piracicaba, São Paulo, 21 jun. 2013. Disponível em: https:// dandonota.wordpress.com/2013/06/21/artigo-jornal-de-piracicaba-11/. Acesso em: 17 jun. 2020.

ARAÚJO, Maria Paula; SILVA, Izabel Pimentel da; SANTOS, Desirre dos Reis (org.). Ditadura militar e democracia no Brasil. Rio de Janeiro: Ponteio, 2013.

BITTENCOURT, Circe Maria. Ensino de História: fundamentos e métodos. 3. ed. São Paulo: Cortez, 2009.

BRAUDEL, Fernand. História e Ciências Sociais: a longa duração. Revista de História, São Paulo, v. 30, n. 62, ano XVI, p. 261-294, 1965.

CARVALHO, Maria Alice Rezende de. Bom para pensar. Boletim Cedes, Rio de Janeiro, jul./set. 2013. Disponível em: http://www.cis.puc-rio.br/cis/cedes/PDF/julho_2013/Artigo\%20-\%20Maria\%20Alice\%20Rezende\%20de\%20Carvalho.pdf. Acesso em: 17 jun. 2020.

CERTEAU, Michel de. A escrita da história. 3. ed. Rio de Janeiro: Editora Forense, 2017.

CLAUDIUS. Teje todo mundo preso! In: CLAUDIUS; JAGUAR; FORTUNA. Hay Gobierno? Rio de Janeiro: Civilização Brasileira, 1964.

FERREIRA, Marieta de Moraes; DELGADO, Lucilia de Almeida Neves. História do tempo presente e ensino de história. Revista História Hoje. São Paulo, v. 2, n. 4, p. 19-34, 2013. Disponível em: https://rhhj.anpuh.org/RHHJ/article/viewFile/90/70. Acesso em: 17 jun. 2020.

GINZBURG, Carlo. Mitos, emblemas e sinais: morfologia e história. São Paulo: Companhia das Letras, 1989.

GOMBRICH, Ernest Hans. Arte e ilusão: um estudo da psicologia da representação pictórica. 4. ed. São Paulo: WMF Martins Fontes, 2007.

GOMBRICH, Ernest Hans. O arsenal do caricaturista. In: GOMBRICH, Ernest Hans. Meditações sobre um cavalinho de pau. São Paulo: Editora da Universidade de São Paulo, 1999. p. 127-142.

GOMBRICH, Ernest Hans. Os usos das imagens. Porto Alegre: Bookman, 2012.

GOMBRICH, Ernest Hans; KRIS, Ernest. The principles of Caricature. British Journal of Medical Psychology, United Kingdom, v. 17, p. 319-342, 1938. Disponível em: https://gombricharchive.files.wordpress.com/2011/05/showdoc85.pdf. Acesso em 17 jun. 2020.

GRUDZINSKI, Silvia Cristina. Critérios jornalísticos de noticiabilidade presentes na rotina produtiva da charge. Biblioteca Online de Ciências da Comunicação, Portugal. p. 1-11, 2009. Disponível em: http://bocc.ubi.pt/_esp/autor.php?codautor=1753. Acesso em: 17 jun. 2020.

KIRALY, Cesar. Antes de toda a memória do mundo. Forma de Vida - Revista do Programa em Teoria Literária da Universidade de Lisboa. Portugal, n. 7, 2016. Disponível em: http://formadevida.org/kiralyfdv7/. Acesso em: 17 jun. 2020.

LE GOFF, Jacques. Documento/Monumento. In: LE GOFF, Jacques. História e memória. 4. ed. Campinas: Editora da Unicamp, 1996. p. 535-549.

LIMA JÚNIOR, Francisco Chagas Vieira. A crítica do relativismo histórico em Carlo Ginzburg. História e-História, Campinas, v. 10, p. 1-16, 2009.

MENESES, Ulpiano Toledo Bezerra de. Rumo a uma “história visual”. In: MARTINS, Jose de Souza; ECKERT, Cornelia; NOVAES, Sylvia Caiuby (org.). O imaginário e o poético nas ciências sociais. São Paulo: Edusc, 2005.

MIANI, Rozinaldo Antônio. Charge: uma prática discursiva e ideológica. 9a Arte, São Paulo, v. 1, n. 1, p. 37-48, 2012. Disponível em: https://www.revistas.usp.br/nonaarte/article/view/99622/98065. Acesso em: 17 jun. 2020.

MONTANARO, João. Decifra-me ou te devoro. Folha de S. Paulo, 22 jun. 2013. Disponível em: http://acervo.folha.uol. com.br/fsp/2013/06/22/2/. Acesso em: 31 jan. 2016.

MONTEIRO, Ana Maria. Tempo presente no ensino de história: mediações culturais no currículo. Anais do XXVI Simpósio Nacional de História. São Paulo, p. 1-16, jul. 2011. Disponível em: http://www.snh2011.anpuh.org/resources/ anais/14/1300914722_ARQUIVO_ANPUHTempopresentenoensinodehistoria-textoAnaMMonteiro.pdf. Acesso em: 17 jun. 2020.

MOTTA, Rodrigo Patto Sá. Jango e o golpe de 1964 na caricatura. Rio de Janeiro: Jorge Zahar Editor, 2006. 
MOTTA, Rodrigo Patto Sá. A ditadura nas representações verbais e visuais da grande imprensa: 1964-1969. Revista Topoi, Rio de Janeiro, v. 4, n. 26, p. 62-85, jan./jul. 2013. Disponível em: https://www.scielo.br/pdf/topoi/v14n26/ 1518-3319-topoi-14-26-00062. Acesso em: 17 jun. 2020.

PANOFSKY, Erwin. Significado nas artes visuais. 3. ed. São Paulo: Perspectiva, 2009.

POCOCK, John Greville Agard; MICELI, Sérgio (org.). Linguagens do ideário político. São Paulo: Ed. Universidade de São Paulo, 2003.

REIS, Daniel Aarão; RIDENTI, Marcelo; MOTTA, Rodrigo Patto Sá (org.). O golpe e a ditadura militar. São Paulo: Edusc, 2004.

SALLUM JÚNIOR, Brasílio. Labirintos: dos generais à Nova República. São Paulo: Hucitec, 1996.

SOUTO MAIOR, Jorge Luiz. Violência silenciosa do Estado (Social) e o grito das manifestações de junho. Congresso Brasileiro de Direito Previdenciário, São Paulo, jun. 2013. Disponível em: https://blogdaboitempo.com.br/2013/08/22/ violencia-silenciosa-do-estado-social-e-o-grito-das-manifestacoes-de-junho/. Acesso em: 17 jun. 2020.

Data de submissão: 19/06/2020

Data de aceite: 03/07/2020 